\title{
Jurors' Perceptions of Preschoolers and Younger School Aged Children's Memory Errors
}

\author{
Emily Margaret Deming \\ West Virginia University, emdeming@mix.wvu.edu
}

Follow this and additional works at: https://researchrepository.wvu.edu/etd

Part of the Child Psychology Commons, Developmental Psychology Commons, and the Other Psychology Commons

\section{Recommended Citation}

Deming, Emily Margaret, "Jurors' Perceptions of Preschoolers and Younger School Aged Children's Memory Errors" (2019). Graduate Theses, Dissertations, and Problem Reports. 3874.

https://researchrepository.wvu.edu/etd/3874

This Thesis is protected by copyright and/or related rights. It has been brought to you by the The Research Repository @ WVU with permission from the rights-holder(s). You are free to use this Thesis in any way that is permitted by the copyright and related rights legislation that applies to your use. For other uses you must obtain permission from the rights-holder(s) directly, unless additional rights are indicated by a Creative Commons license in the record and/ or on the work itself. This Thesis has been accepted for inclusion in WVU Graduate Theses, Dissertations, and Problem Reports collection by an authorized administrator of The Research Repository @ WVU. For more information, please contact researchrepository@mail.wvu.edu. 
Jurors' Perceptions of Preschoolers and Younger School Aged Children's Memory Errors

\author{
Emily Deming
}

Thesis submitted

to the Eberly College of Arts and Sciences

at West Virginia University

in partial fulfillment of the requirements for the degree

Masters of Science in

Psychology

Elisa Krackow, Ph.D., Chair

Constance Toffle, Ph.D.

Amy Fiske, Ph.D.

Department of Psychology

Morgantown, West Virginia

2019

Keywords: Jurors' Perceptions, Memory Errors, Age Differences, Developmental Differences, Preschoolers, School Aged Children

Copyright 2019 Emily Deming 


\begin{abstract}
Jurors' Perceptions of Preschoolers and Younger School Aged Children's Memory Errors

Emily Deming
\end{abstract}

The purpose of this study was to examine jurors' perceptions of different types of memory errors in the context of a child recalling information about alleged maltreatment. Additionally, this study assessed whether developmental differences in memory errors affect jurors' perceptions of the child, the external influences that may be affecting the child, and the defendant. Participants ( $N=372$ ) were randomly assigned to one of eight vignettes that contained three different memory errors (major reconstructive memory error, minor reconstructive memory error, source monitoring error) or a control condition (no memory error), as well as two age groups (4-year-old child and 6-year-old child). After reading the vignettes, participants answered questions that addressed the credibility of the child, the external influences that may be affecting what the child remembers, and the guilt of the defendant. The participants answered dichotomous questions that assessed defendant guilt and child credibility. This study found that regardless of type of memory error or age of the child, if a child engaged in any of the aforementioned memory errors they were seen as less credible, more subject to external influences, and the defendant was rated as less guilty. When a child engaged in a major reconstructive error or a source monitoring error, the juror was more likely to rate the defendant as not guilty. When the child made a memory error, the potential juror was nearly 5 times more likely to rate the child as not credible. This study shows that jurors are not discriminating between types of memory errors. 


\section{Table of Contents}

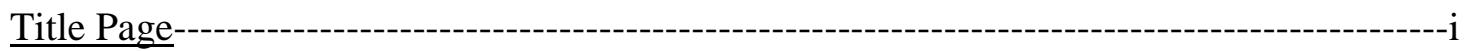

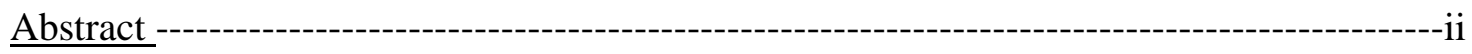

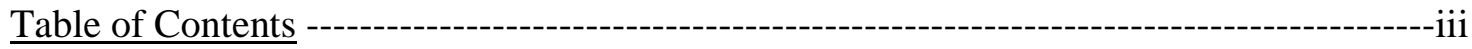

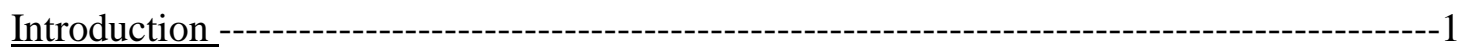

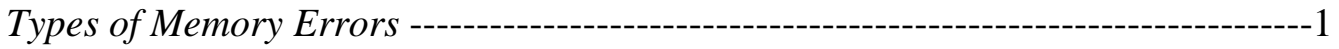

Reconstructive Memory Errors in Children and Adults ------------------------1

Source Monitoring Errors ---------------------------------------------------------- 4

Link between Source Monitoring and Suggestibility ----------------------------------- 5

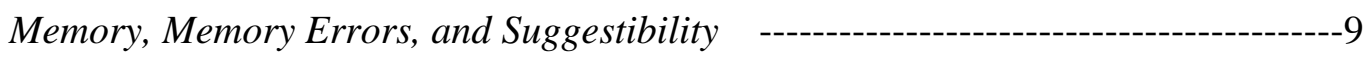

Jurors’ Perceptions of Age Differences --------------------------------------------------13

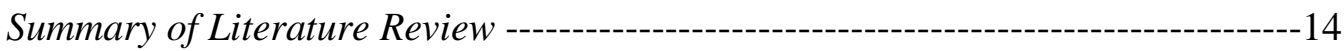

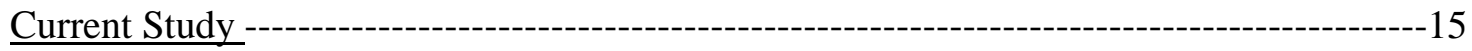

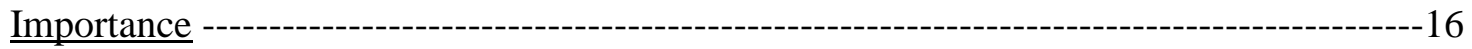

Research Questions and Hypotheses ---------------------------------------------------------------16

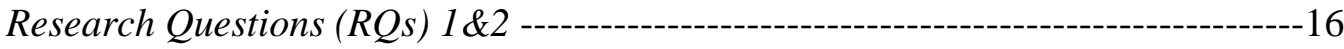

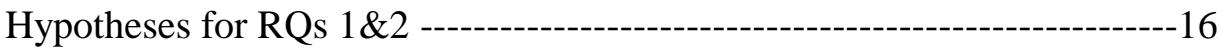

Research Question (RQ) 3 -----------------------------------------------------------------17

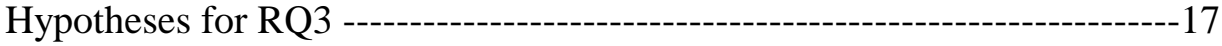

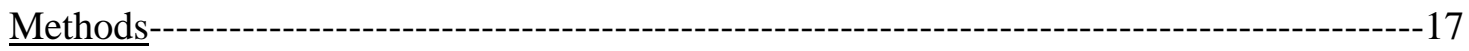

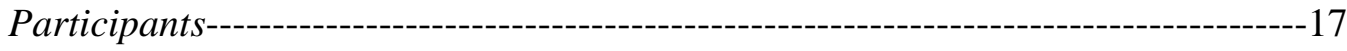

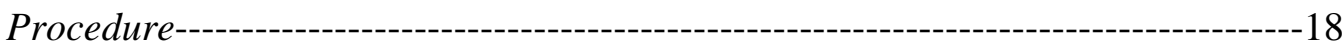

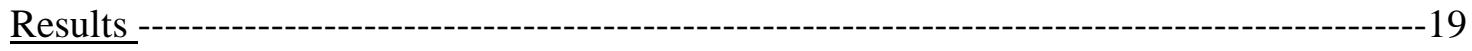

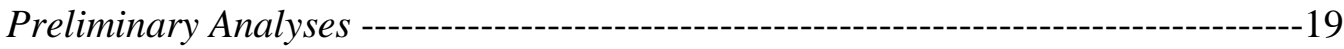

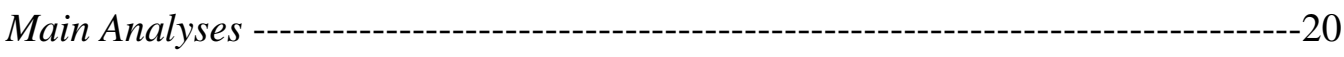

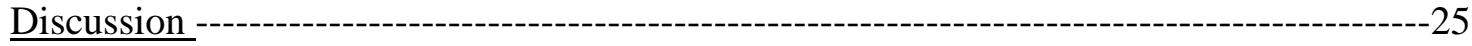

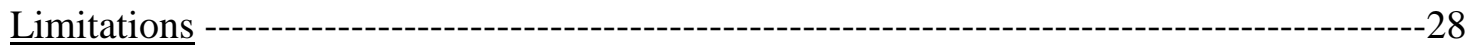

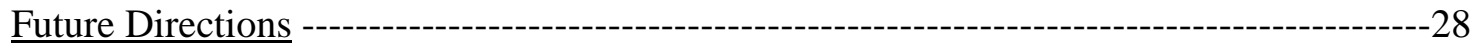

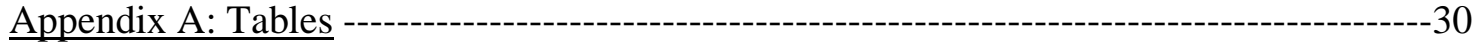

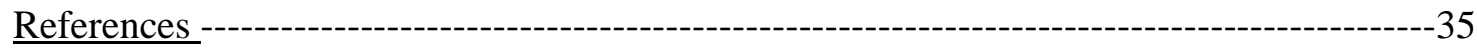




\section{Introduction}

Eyewitness testimony has the potential to be one of the most important components of a criminal trial. Jurors rely on eyewitness testimony to provide them with a snapshot of the alleged crime, presumably given by a person that was present when the crime occurred (Wise, Fishman, \& Safer, 2009). However, there is a fatal flaw with eyewitness testimony; memories can be manipulated and are extremely susceptible to errors (Wise et al.). One population that must give in-courtroom testimony in order to ensure that the perpetrators are convicted are children who allege abuse. The National Children's Alliance reported that annually in the U.S. nearly 700,000 children per year have founded reports of abuse by Department of Children and Family Services (includes physical, verbal, and sexual abuse).

The purpose of this study is to examine jurors' perceptions of different types of memory errors. In addition, this study examines whether developmental differences in memory errors impact jurors’ perceptions.

\section{Types of Memory Errors}

\section{Reconstructive Memory Errors in Children and Adults}

Brainerd and Reyna (1998) assert that people store a verbatim representation of a past event that includes details of that event, and also a more vague or generic gist representation of that same past event. When attempting to retrieve both of the representations, there are two factors that are extremely important regarding whether the attempts are successful. The first factor involves the retrieval cues that are given to the individual (Brainerd \& Reyna). The second factor is the variability between the forgetting rates of verbatim and gist traces (Brainerd \& Reyna). The second factor is especially important because it has been shown that verbatim traces fail at a faster rate when compared to gist traces until verbatim traces are no longer available (Brainerd \& Reyna). Therefore, the longer the delay between the time when a memory is 
encoded and the time when it is recalled, the less likely people are to recall verbatim details and the more likely people are to remember the general outline of the event.

When assessing the relevant literature, it is clear that both adults and children are prone to making reconstructive errors (Brainerd \& Reyna, 1998; Hudson, 1990). Reconstructive errors have been shown to occur as memory becomes more gist-like (Hudson, 1990). A reconstructive error occurs when an individual attempts to recall details about an event and those details change from the original event. A landmark study by Hudson (1990) that demonstrated this phenomenon included a sample of 60 children who were in preschool and 58 children who were enrolled in kindergarten. All children were exposed to a workshop that included singing, dancing, and movement games. The children either participated in one workshop (considered the episodic condition) or they completed four workshops (considered the repeated condition). In the repeated condition all four workshops maintained a consistent format with all activities remaining the same. At first the children were asked general questions (e.g. "What happened in the workshop today?” Hudson, 1990, p.181) and then the children were asked specific questions (e.g. "What songs did you sing?” Hudson, 1990, p.181). All children were then interviewed by an experimenter, 1 week and 3 weeks after the final workshop. Children who were in the repeated condition were asked about the activities that occurred in either the first or the last workshop. The children who were in the episodic condition were asked what occurred in the workshop. Hudson (1990) found that regardless of age, children were able to recall more about a particular episode if they were in the repeated condition. Children in the repeated condition were able to recall more details about the particular event but were more likely to confuse details between the episodes. The results of this study indicate that children in the repeated condition produced 4 times as many reconstructive errors than their peers in the episodic condition. When 
the children were asked a specific question, reconstructive errors became more prevalent in their responses.

The Hudson (1990) study showed that when events occur multiple times a child is more likely to make reconstructive errors. What was not assessed was how an emotion tied to an event could affect memory errors. This next study assesses this aspect of an event recall.

A study conducted by Krackow, Kania, and Travers (2012) investigated the effects of mood congruent recall on the quality of memory recall as well as the accuracy of the memory. This study utilized a sample of 42 undergraduate students who in the first session were randomly assigned to and underwent a positive or negative mood induction. Immediately after undergoing the mood induction all participants listened to a CD that contained 11 narratives about a male college student and his experiences. Seven days after their first session all participants were invited to return to the lab; in the second session the participants underwent the same mood induction they experienced in the first session. After undergoing the mood induction all participants were asked to recall and write down specific details about all events from the CD they listened to in the first session.

The results from this study indicate that errors in memory reconstructive process were prevalent and were equivalent for both the positive and negative mood induction groups when the participants were asked open-ended recall questions (Krackow et al., 2012). For example, some participants recalled methods of notification (i.e. a phone call regarding the death of a family pet) that were never explicitly mentioned, and some participants incorrectly recalled which car hit another car.

When an emotion is tied to a memory or an event there is a fair chance that memory would meet the criteria for a flashbulb memory. While this previous study did not assess 
flashbulb memories, this next study investigated how the reconstructive process is affected when attempting to recall flashbulb memories.

A study conducted by Krackow, Lynn, and Payne (2005) examined the prevalence of memory reconstruction errors by assessing flashbulb memories. Flashbulb memories are memories tied to an event that holds significant emotional value (Brown \& Kulik, 1977). Flashbulb memories were originally thought to be free from reconstructive errors (Brown \& Kulik). The Krackow, Lynn, and Payne study identified errors that were present when comparing the flashbulb memories of Princess Diana’s death from early after the event occurred and the flashbulb memories from 11-12 weeks after the event occurred. These errors occurred (only 32\% of the information was consistent) when the complete time 2 narratives were compared to the time 1 narratives. Some of the inconsistencies represented major reconstructive errors such as how they learned the news of Princess Diana’s death and some represented minor reconstructive errors such as indicating they were watching CNN when they were actually watching FOX news.

In summary, it is important to note that reconstructive memory errors are present regardless of age and regardless of emotional context.

\section{Source Monitoring Errors}

Source monitoring, the activity of making attributions about the origin of experiences and memories, is an essential ability in everyday life in addition to being a critical component of memory. Source monitoring is the ability to determine how an individual acquired certain knowledge (Johnson, Hashtroudi, \& Lindsay, 1993). Source monitoring errors are generated when a person incorrectly attributes a memory to the wrong source. An example of a source monitoring error would be if a person repeats a joke to a friend who originally told the joke to them, but tells it anyway because they believe they heard it from another person. Often these 
errors of incorrectly identifying a source are brought about by names or situations that seem familiar to that person because of recent exposure. Source errors do not occur due to solely outside influences. There is also significant evidence that these errors can have roots in dysfunction of certain brains areas, namely the frontal lobe. It is extremely important to focus on the fact that source monitoring errors are not due to one particular factor; it is a combination of factors that contribute to the error. These factors can be divided into two main categories. The first is an interruption in the encoding process and the second is a disruption of the sourcemonitoring process. This first interruption occurs towards the beginning of the memory formation process. It is a failure to properly encode the information/memory and this can lead to errors when an individual attempts to recall that memory. The second interruption occurs during the recall portion of the process. This can happen when an individual attempts to recall the source from which they heard/saw a piece of information and there is interference with information from another memory.

\section{Link between Source Monitoring and Suggestibility}

Understanding source monitoring and the errors that can be made is essential to understanding how source monitoring plays a role in suggestibility. Lindsay and Johnson (1989) assert that the confusion of memories from different sources could possibly contribute to suggestibility. Lindsay and Johnson (1989) utilized a design where all participants were presented with information either in a picture, within narrative text, both within a picture and narrative text, or none of the above. After that information was presented, participants engaged in either a source monitoring task or a yes/no recognition task. In the source monitoring task, participants selected a response from the four previously stated options, (e.g. Picture, Text, Both or None) that best indicated the stimulus within which they had previously seen the selected 
item. In the yes/no recognition task, participants indicated whether or not they had previously seen the selected item. In between participants' viewing of pictorial information and completing the source monitoring or yes/no recognition task, participants read one of two narrative options. One narrative option was a control and contained no misleading information; the second option contained misleading information. The results of this first experiment indicated that participants who completed the yes/no recognition task and read the misleading narrative were significantly more likely to identify suggested items as items they had previously seen when compared to participants who completed the yes/no recognition task and did not have a misleading narrative. The results from the first experiment also indicated that those who engaged in the source monitoring task and read the misleading narrative were significantly less likely to identify misleading items as original items compared to participants who completed the yes/no recognition task and read a narrative that contained misleading information.

A second experiment was conducted in order to control the variability that the instructions could introduce. The instructions were changed in order to ensure that the participants were not warned that the questions contained misleading information (Lindsay \& Johnson, 1989). The results of Experiment 2 yielded very similar results to Experiment 1 . Those who read the narrative claimed to have seen significantly more of the suggested items than the participants in the other condition. Overall, the results from the two experiments showed that when a subject was asked to identify the source of the item, they were less likely to misattribute the source of the suggested item than if they were not asked to identify the source of the item. Asking a person to think critically about the source of the information they are identifying can be key to helping combat some of the effects of suggestibility. 
Convergent evidence has been shown by Zaragoza and Lane (1994). The results of the study indicated that participants who engaged in a source-monitoring task attributed suggested items to the presented information with less frequency compared to peers who did not participate in a source-monitoring task.

Additional evidence has shown that children aged 3 years are more susceptible to suggestibility, but suggestibility in children aged 7 is not as likely as when the child is preschool aged (Welch-Ross, Dieciude, \& Miller, 1997). For the purposes of the experiment conducted by Welch-Ross, Diecidue, and Miller, 42 preschool children were recruited to participate in the study. In session 1 of the study all children listened to a four sentence story and then answered four yes or no questions relating to the study. The first experimenter then read to the child a 240word story about what a girl named Sally did on her day off of school. After the children listened to the story they began working on a puzzle; after 2 minutes the first experimenter left the room and second unknown experimenter entered the room. Once the second experimenter entered the room the child continued to work on the puzzle for another two minutes; after the two minutes were up the experimenter asked the child 29 yes or no questions about the story they had listened to from the first experimenter. Eighteen of the questions did not contain misleading information while eleven of the questions contained misleading information. In the second session of the experiment, approximately 6-9 days later, the children answered the same 29 questions again. The children also completed an appearance-reality task, which could be conceptualized as a source monitoring task, in order to determine that the children are able to differentiate between what an object is and what they believe it to be. The results from this study indicated that the 3year-old group was more suggestible when compared to the 7-year-old age group. Another important finding was that when suggested information was introduced during the questioning, 
the 7-year-old group was better able to resist the misleading information than the 3-year-old group. Further, performance on the appearance reality task was highly dependent on age and predicted suggestibility. Children who showed mastery of the appearance reality concept were older and were less suggestible.

Giles, Gopnik, and Heyman (2002) make the assertion that source monitoring tasks can help to reduce the effect of suggestibility in preschool aged children. To test this, the authors had 32 preschool children watch silent video and listen to a spoken narrative read by the experimenter about a young boy feeding his dog. Each child was read the story and after the story each child was assigned to a condition and partook in the tasks associated with that condition. During the source monitoring task, children were asked a general question followed by a question that asked the children to identify the source from which that the information originated. Participants who engaged in a source-monitoring task prior to the suggestive questioning task were less suggestible when answering misleading questions compared to their peers who completed an unrelated task. These results are important because they further show that when someone is asked to think critically about the source from which information originated they are less likely to be susceptible to suggested or misleading information. In a similar study (Thierry \& Spence, 2002) researchers assigned 3-and-4 year olds to a source monitoring or control condition followed by an examination of suggestibility. Children who partook in the source monitoring task were significantly less suggestible.

In summary, these previously reviewed studies show an important link between a person's source monitoring ability and how likely they are to take suggested information as actually occurring information. The results of these studies indicate that as a person focused on 
where they learned the information from they are less likely to take misleading information as information that occurred in the target event.

\section{Memory, Memory Errors, and Suggestibility}

Ceci and Bruck (1995) in Jeopardy in the Courtroom bring forth the about-to-bedescribed evidence to why preschoolers are more susceptible to memory errors and suggestibility when compared to older children. One main component of memory that plays an important role is semantic memory. Semantic memory is defined as the ability to store facts and understand the structure of events. A young child when compared to an older child has limited semantic knowledge and memory capability, thereby rendering younger children especially susceptible to suggestive information. Another important part of understanding age differences in memory is scripted knowledge. This is a person's habitual, temporally organized understanding of what typically happens within a particular event context. Scripted knowledge is also a key component. Scripted knowledge leads an individual to make automatic assumptions about how a particular event should have played out and can lead to reconstruction errors when questioned about it later. A younger child can often have poor script knowledge when compared to an older child and thus can lead to the young child making more inferences about what actually occurred during the event. Deficits in semantic and scripted knowledge that are present in younger children help to explain why these younger children are more susceptible to taking suggested content as their own memory. It is also important to note that script knowledge can have the opposite influence on memory accuracy. The following studies described below provide evidence to document age differences in memory. Even though numerous research studies have shown that there are age differences in memory and suggestibility, children 7 years and older can be suggestible with script knowledge still playing a role in memory errors. In a study of 
susceptibility to suggestion in which participant children (aged 7 and 11) had personally experienced or had not experienced three specific life events. Children with more developed script knowledge were more susceptible to incorporating additional experimenter-generated event details into their memory reports of two events that they had experienced, and were more susceptible to reporting memories of one never-experienced event (Otgaar, Candel, Scoboria, and Merckelbach, 2010).

Goodman and Reed (1986) explored how age differences affected a person’s testimony. This particular study utilized a sample of 3 year olds, 6 year olds, and adults. All three groups interacted with a stranger, a confederate for the study, for approximately five minutes (Goodman \& Reed, 1986). The child interacted with the confederate via conversation in which the confederate asked the child several questions (e.g., "What is your name? "How old are you?” Goodman \& Reed, 1986, p. 323) then the confederate taught the participant a game. Approximately four to five days after this first session the children returned to the lab and were questioned. The children were asked general questions about what happened during their first visit to the lab. The experimenter then followed up with more specific prompts about what happened on the first visit (e.g. "What did the man look like?” "What was in the room?” Goodman \& Reed, 1986, p.323), followed by yes-no questions. The questions to which "no" was the correct answer contained misleading information and therefore were considered suggestive in nature.

When compared to the 6- year- old group, the 3- year-olds were able to recall less about the event in response to general questions and were more susceptible to the suggested information. This study produced important results because it draws attention to the point that 
preschool children are less likely to recall as much from an event and the information they provide is especially vulnerable to suggested information provided in questions.

Goodman continued her work in 1991 with her colleagues to better understand how age differences play a role in the accuracy of a child's memory reports especially under stressful situations (i.e. visiting a clinic for a shot or blood drawing in order to assess how stress affects memory); (Goodman, Hirschman, Hepps, and Rudy, 1991). Study 1 utilized a sample of children who did not have any medical conditions and their ages ranged from 3 years to 7 years. The first study used venipuncture (drawing blood from a vein using a needle) as the target event. Children were randomly assigned to either a group that received venipuncture or a group that had the same process except they did not have any blood drawn. Instead the lab technician rubbed a design on their arm. Approximately three to four days later, the children were asked some general questions about the last time they were in the clinic. After the general prompts the experimenters asked the children specific probes as well as misleading questions. The results showed that the 7year-old group was more accurate in response to specific questions and less suggestible than was the 3-year-old group. Goodman and colleagues did not report on age differences in free recall. This is possibly because errors in free recall were not made frequently enough to analyze.

A second study was conducted due to the limited sample size used in the first study and due to the fact that the medical staff were trained in calming techniques which mitigated the stress the participants were experiencing. In Study 2, children received inoculations instead of venipuncture because inoculations produce a greater amount of stress and are so routine that studying memory for this event allowed for recruitment of a large sample of children (Goodman et al., 1991). Study 2 involved two samples of children, a 3-to-4-year-old group and a 5-to-6year-old group. This second phase was very similar to the first phase except that instead of 
having blood drawn, the children were given vaccines and there was either a short delay (3-4 days) between appointments or a long delay (7-9 days). This study found that the older age group was more accurate when compared to the younger age group when answering the specific questions as well as the misleading questions. The results of the study also show that when age differences were compared across free recall questions, there were no differences.

Another study that provides key evidence was conducted by Krackow and Lynn (2009), who assessed the use of Event Report Training as a way to reduce suggestibility in addition to improving the quality of memory reports. This study consisted of 58 children who ranged from preschool aged to school-aged. During the first session, the children met with a research assistant, engaged in a pretend visit to a beach, and played a game, called shapes. The children were shown a video and were asked yes or no questions about the video. The children were randomly assigned to an Event Report Training (ERT) condition or the control condition. Event Report Training involves components of modelling as well as practice and feedback in regards to a child's ability to recall target events when asked open-ended questions. Immediately after the ERT and control procedures, children were interviewed by a female research assistant about what needed to be done in order to pretend visit the beach or play the shapes game. After the participants had any opportunity to answer the open ended questions, all participants were asked 27 yes or no questions about what did and did not occur during the play session with the research assistant. Fourteen of the questions were correctly leading questions while 13 of the questions were misleading. Of the fourteen questions a few involved asking about innocuous touches made during the event.

This study found that 7-to-8-year-old children in the control group who did not undergo training to bolster their open-ended question reports recalled less information than 7-to-8-year- 
old children who underwent ERT (Krackow \& Lynn, 2009). The 7-to-8-year-old group recalled significantly more information than the 4-to-5-year-old group when they were asked open-ended questions. Another important finding of this study was that the 4-5-year-old children in the ERT condition were less likely to accept misleading information when compared to the 4-5-year-old children who were in the control condition. These results show that an older child will produce more information when presented with open ended questions. When older children are presented with a misleading question, they will not take the suggested information as true.

The most important idea to take away is that these studies show a definitive connection between age, memory recall, and suggestibility. Younger children (3-to-4-year-olds) recall less information when asked general questions; recall less when asked more specific questions; and are more suggestible when given misleading questions compared to 6-to-8-year-olds.

\section{Jurors’ Perceptions of Age Differences}

Although numerous studies exist that examine jurors’ perceptions of age differences between children and adults, only two focus on differences between the ages of three and seven years. A study conducted by Goodman et al., (1987) was the first to show how age differences can affect the jurors' perception of the witness. This study utilized a written description of a vehicular homicide and each participant read the transcript and had to rate the degree of guilt for the defendant and the credibility of each witness that testified. All participants were given a script to read that included a brief description of the trial and it included the testimony given by the witness that was described to be either 6,10 , or 30 years old. The credibility of the eyewitness increased as age increased. The 6-year-old witnesses were rated as less credible when compared to the 10-year-old group. 
Castelli, Goodman, and Ghetti (2005) conducted a study to assess how jurors differ in their perceptions of the credibility of the child witness and if these perceptions differ based on the age of the witness. In the experiment the researchers utilized a sample of 140 undergraduate students. All participants were randomly assigned to experimental condition that varied age group (i.e. 4-year-old witness or 7-year-old witness), type of questioning (i.e. highly leading, intermediately leading, or less leading), and gender of participant. Participants read a case scenario and were asked to fill out questionnaires that assessed the credibility of the witness (e.g. “How credible were the child's statements?” "How confident were the child's statements?” Castelli et al, 2005, p. 303). Questions including but not limited to the ones previously stated were used to generate a composite credibility score that was used for the results section. The results of the study indicated that jurors perceived 4-year-olds to be more susceptible to suggestive questioning and therefore perceived them as less credible when compared to the 7year-old group.

In summary, jurors are more likely to perceive 3-to-4 year olds to be more susceptible to suggested information and were rated as less credible by the jurors than children aged 6-to-8 years.

\section{Summary of Literature Review}

All these results indicate that there are consistent findings across the field of psychology and across studies. It has been shown that if a person thinks critically about where they learned a piece of information they are less likely to accept misleading information as true information. The previously mentioned results also indicate that younger children will recall less information in general, will struggle to recall specific information, and will be more likely to perceive misleading information as true information when compared to older children. It is also essential 
to acknowledge that jurors in general are likely to perceive 3-to-4 year olds as more susceptible to misleading information and less credible when compared to 7-to-10-year-old children. However, not enough information in the literature exists to make a hypothesis about whether jurors generally believe 6-year-olds more than 4-year-olds.

\section{Current Study}

The current study examined jurors’ perceptions of various types of memory errors (i.e., Source monitoring suggestibility, Major Reconstructive, and Minor Reconstructive) and whether age differences interact with these types of errors. Based on the previously cited literature, the research shows that people, including children, are prone to memory errors including source monitoring suggestibility errors and errors that can be more or less serious (i.e. major or minor reconstructive errors; e.g., Krackow et al., 2005; Hudson, 1990). Limited extant research shows that in a series of studies, jurors are sensitive to one type of memory error, that being factual autobiographical recall errors (Krackow, 2018). In these two studies, when a 6-year-old child made factual autobiographical recall errors, defined as errors made in response to basic questions about their lives (Bruck, London, Landa, and Goodman, 2007), jurors perceived the child as being less credible, more subject to external influences, and the defendant as being less guilty (Krackow, 2018). Krackow, 2018, Study 2 showed that memory errors predicted whether the juror perceived the defendant as guilty or not guilty, but Study 1 did not show these findings. Therefore, it is important to continue to examine jurors' perceptions of memory errors in children. Given that age differences exist such that preschool aged children are more likely to make memory errors than are school aged children, it is important to determine whether jurors are more or less forgiving of young children's memory errors. These research questions have been examined within the context of child sexual abuse allegations. Krackow $(2015,2018)$ 
recommends that prior to making a report to Child Protective Services, interviewers gather data that speaks to the context of maltreatment allegations, including obtaining information that addresses the "wh" questions (who, what, when, and where). The current study employed scenarios in which, in the experimental conditions, a child makes memory errors in response to the "when” question. These errors may serve to call into question the credibility of the child's maltreatment allegation.

\section{Importance}

The results from this study may help to change perceptions of eyewitness testimony given by children. It could make attorneys and potential jurors aware of how common memory errors can be and how different age groups may be viewed differently. This study is the first of its kind to draw attention to different types of memory errors and how they could possibly be perceived differently depending on the child's age. The results from this study could be used to educate attorneys on how the jury could be perceiving these children.

\section{Research Questions and Hypotheses}

RQs1\&2: Do different types of memory errors (i.e. source monitoring suggestibility, major reconstructive, and minor reconstructive) influence jurors’ perceptions of child credibility, perceptions of children's susceptibility to external influences, and perceptions of defendant guilt? Does age (4-year-old vs. 6-year-old) interact with jurors' perceptions of these various types of memory errors?

Hypotheses for RQs 1\&2: Based on Krackow (2018), it is hypothesized that the 6-year-old child witness in the three memory error conditions will be rated by mock jurors as less credible, more subject to external influences, and the defendant will be rated as less guilty when compared to the control condition. Based on the inconsistent findings across the two studies by Krackow 
(2018), no hypotheses will be made about age, memory errors, nor age by memory error interactions in the prediction of defendant guilt when a guilty vs. not guilty outcome measure is employed. No hypotheses will be made about whether differences will exist between the memory error conditions and the control condition when a 4-year-old is depicted as the witness. RQ3: Do types of memory error, age, and their interactions predict dichotomous defendant guilt (guilty vs. not guilty)?

Hypotheses for RQ3: Based on the inconsistent findings across studies within Krackow (2018), no hypotheses will be made about age, memory errors, nor age by memory error interactions in the prediction of defendant (guilty vs. not guilty).

\section{Methods}

\section{Participants}

The total sample for this study consisted of 372 participants. $41.1 \%$ (153) of the participants were female and 58.9\% (219) participants were male. The mean age for this sample was 37.64 years ( $\mathrm{SD}=11.011)$. The youngest participant was 20 years old and the oldest participant was 79 years old. The sample of this study was predominately Caucasian (77.4\%). Seven and a half percent identified as African-American, 8.1\% identified as Asian, 4.3\% identified as Hispanic/Latino(a), 1.9\% identified as biracial, and 0.8\% identified as American Indian. There were 186 participants randomly assigned to the 6-year-old condition and 186 participants randomly assigned to the 4-year-old condition. There were 75 participants randomly assigned to the Major Reconstructive error condition, 93 participants randomly assigned to the minor reconstructive error condition, 96 participants were randomly assigned to the source monitoring error condition, and 108 participants were randomly assigned to the control 
condition. Participants $(N=209)$ were excluded from the analyses due to the participants failing validity checks and/or completing the survey in under 100 seconds.

\section{Procedure}

Participants were randomly assigned to read one of eight total scenarios regarding a child who makes an abuse allegation against her father to her mother (Krackow, 2018). The scenarios will vary on age (4-year-old and 6-year-old) and types of memory error (source monitoring error, major reconstructive error, minor reconstructive error, and a control condition). After the child makes the disclosure, the mother asks a follow-up question about when the alleged maltreatment occurred. In responding to the follow-up question, in the major reconstructive error condition, the child makes a major reconstructive error, the child says the mother was at work when the mother does not work outside of the home. In the minor reconstructive error condition, the child confuses the mother's vacation location at the time of the alleged maltreatment and indicates the incorrect vacation location (which speaks to the timing of the event). In the source monitoring suggestibility condition the mother suggests a vacation location, corrects her suggestion, and asks about a new vacation location. The child says yes in response to questions about the second and third vacations (which speaks to the timing of the event). In the control condition, the mother does not ask a follow-up question and the child does not make a memory error.

Following reading the scenario, participants answered three comprehension questions. These comprehension questions had the participant recall information about the aspects of the key event (e.g. alleged perpetrator, age of the child; Tessier \& Krackow, 2013). The participants then answered three questions that assessed the credibility (child credibility, believability, and trustworthiness) of the witness [e.g. "on a scale from 1 (not at all credible) to 10 (there is no doubt in my mind that this child is credible”) Tessier \& Krackow, 2013]. The participants also 
answered three questions about defendant guilt, likelihood that the defendant committed the act in question, and how responsible was the defendant for the alleged crime (Tessier \& Krackow, 2013; Krackow, 2016). There were also two questions that ask about external influences on the testimony provided by the witness. These questions assessed if the participant believed that the witnesses memories were created by the influence of other people and the likelihood that the child's accusations in this case is a result of the child being suggestible (Orcutt et al., 2001; Krackow, 2016; Krackow, 2018). There was a dichotomous question where the participants indicate if they believed the defendant was guilty or not guilty. The final question was dichotomous and participants were asked to indicate if they believed the child was credible or not credible.

All participants then read two unrelated scenarios to further rule out data from participants who were not attending to the material (Krackow, 2018). They then answered three questions for the first scenario and two questions for the second scenario. At the end of the survey there was demographic questions that assess age, ethnicity, and gender (Krackow, 2018). Participants were paid \$1.00 for participation in the study.

\section{Results}

\section{Preliminary Analyses}

Skew and Kurtosis values and outliers were generated for all variables used in the following analyses. All values were within normal limits and no changes to the data were made.

A Pearson two-tailed correlation analysis was conducted between participant age and child credibility to determine whether participant age needed to be used as a covariate. Participant age and child credibility had a significant negative correlation at the .01 level ( $r=$ 0.139, $p<0.01)$. A Pearson two-tailed correlation analysis was also conducted between 
participant age and defendant guilt. Participant age and defendant guilt had a significant negative correlation $(r=-0.167, p<0.01)$. A final Pearson two-tailed correlation analysis was conducted between participant age and external influences. Participant age and defendant guilt had a significant positive correlation $(r=0.156, p<0.01)$. Although participant age was significant, the correlations were small and it was decided not to use participant age as a covariate.

In order to determine whether gender needed to be included as a variable in the Analyses of Variance (ANOVAs), an effect size was generated comparing male and female participants on the child credibility composite score. The Cohen's $d$ value ( $r=0.4759)$ indicates a moderate effect of gender on child credibility. An effect size was also generated to compare male and female participants on their ratings of defendant guilt. The Cohen's $d$ value $(r=0.4527)$ indicates a moderate effect of gender on ratings of defendant guilt. An additional effect size value was generated to compare male and female participants on their ratings of external influences on the child's testimony. The Cohen's $d$ value ( $r=-0.3097)$ indicates a small effect of gender on ratings of external influences on the child's testimony. Because of these moderate effect sizes it was determined that gender should be included as a variable in the ANOVAs

\section{Main Analyses}

Initially all ANOVAs were run as 2 child age ( 4 vs. 6 years old) x 4 type of memory error (major reconstructive error, minor reconstructive error, source monitoring error, control condition x 2 gender (male vs. female), so that gender was included in the analyses. Gender did have a significant main effect across child credibility, defendant guilt, and external influences. The composite scores for child credibility was generated by adding together the participants 1 to 10 response to each of the three questions for child credibility. Those summed scores were then divided by the number of questions used to generate the summed score The same procedure was 
followed to generate the defendant guilt composite (3 questions) and the external influences composite (2 questions). Upon further review gender did not have any significant interaction effects and did not add any unique information to the ANOVAs. Because participant gender was not significant past a main effect it was excluded from the analyses and all ANOVAs were run using the 2x4 model.

A 2 child age ( 4 vs. 6 years old) x 4 type of memory error (major reconstructive error, minor reconstructive error, source monitoring error, control condition) ANOVA was conducted to determine the main effects on child credibility. This analysis produced a non-significant Levene's Test of Equality of Error Variances $[F(7,364)=1.189, p=0.308]$. The age main effect was not significant $\left[F(1,372)=0.737, p=0.391, \eta_{\mathrm{p}}{ }^{2}=0.002\right]$ (See Table 1 for means and standard deviations). The main effect of memory error was significant at the $[F(3,372)=13.35, p<0.001)$, $\left.\eta_{\mathrm{p}}{ }^{2}=0.099\right]$ (See Table 2 for means and standard deviations). The interaction effect between age and memory error was not significant as well $\left.[F(3,372)=0.383, p=0.765), \eta_{\mathrm{p}}{ }^{2}=0.003\right]$ (See Table 3 for means and standard deviations).

Because the memory error condition was the only significant condition, further analyses were only conducted with this variable. Post hoc analyses were conducted using the Bonferroni correction. These Tukey-b post hoc analyses indicated that there was a significant mean difference between the major reconstructive error condition and the control condition $(M=-2.005$ [-2.979, -1.031], $p<0.001, d=-0.851)$. There is also a significant mean difference between the minor reconstructive error condition and the control condition $(M=-1.690[-2.607,-0.774]$, $p<0.001, d=-0.706)$. The final significant mean difference was between the source monitoring error condition and the control condition $(M=-1.693$ [-2.602, -0.784$], p<0.001, d=-0.703)$. There were no significant mean differences between the memory error conditions. 
A 2 child age ( 4 vs. 6 years old) x 4 type of memory error (major reconstructive error, minor reconstructive error, source monitoring error, control condition) ANOVA was conducted to determine the main effects on defendant guilt. This analysis produced a non-significant Levene's Test of Equality of Error Variances $[F(7,364)=0.800, p=0.588]$. The age condition main effect was not significant $\left[F(1,372)=2.910, p=0.089, \eta_{\mathrm{p}}{ }^{2}=0.008\right]$, but there was a trend for the defendant to be perceived as more guilty when the child witness was age 4 compared to age 6 (See Table 4 for means and standard deviations). The memory error condition main effect was significant $\left[F(3,372)=12.588, p<0.001, \eta_{\mathrm{p}}{ }^{2}=0.094\right]$ (See Table 5 for means and standard deviations). The interaction effect between age and memory error was not significant $[F(3,372)$ $\left.=0.674, p=0.568, \eta_{\mathrm{p}}{ }^{2}=0.006\right]$ (See Table 6 for means and standard deviations).

Because the memory error condition was the only significant condition, further analyses were only conducted with this variable. Post hoc analyses were conducted using the Bonferroni correction. These Tukey-b post hoc analyses indicated that there was a significant mean difference between the major reconstructive error condition and the control condition $(M=-2.084$ [-3.086, -1.081], $p<0.001, d=-0.845)$. There is also a significant mean difference between the minor reconstructive error condition and the control condition $(M=-1.579[-2.522,-0.635]$, $p<0.001, d=-0.642$ ). The final significant mean difference was between the source monitoring error condition and the control condition $(M=-1.568[-2.504,0.632], p<0.001, d=-0.634)$. There were no significant mean differences between the memory error conditions.

A 2 (Child age [4 vs. 6 years old]) x 4 (Type of Memory Error [major reconstructive error, minor reconstructive error, source monitoring error, control condition]) ANOVA was conducted to determine the main effects on External Influences on the child's testimony. This analysis produced a non-significant Levene’s Test of Equality of Error Variances $[F(7,364)$ 
$=0.410, p=0.896]$. The age main effect was not significant $[F(1,372)=0.266, p=0.606$, $\left.\eta_{\mathrm{p}}{ }^{2}=0.001\right]$ (See Table 7 for means and standard deviations). The main effect of memory error was significant $\left[F(3,372)=14.845, p<0.001, \eta_{\mathrm{p}}{ }^{2}=0.109\right]$ (See Table 8 for means and standard deviations). The interaction effect between age and memory error was not significant as well [F $\left.(3,372)=0.597, p=0.617, \eta_{\mathrm{p}}{ }^{2}=0.005\right]$ (See Table 9 for means and standard deviations).

Because the memory error condition was the only significant condition, further analyses were only conducted with this variable. Post hoc analyses were conducted using the Bonferroni correction. These Tukey-b post hoc analyses indicated that there was a significant mean difference between the major reconstructive error condition and the control condition $(M=1.629$ [0.695,2.563], $p<0.001, d=0.704)$. There is also a significant mean difference between the minor reconstructive error condition and the control condition $(M=1.948$ [1.069, 2.827], $p<0.001$, $d=0.849$ ). The final significant mean difference was between the source monitoring error condition and the control condition $(M=1.821[0.949,2.693], p<0.001, d=0.798)$. There were no significant mean differences between the memory error conditions.

A logistic regression was conducted to determine if child age and type of memory error predicted defendant guilt (guilty vs. not guilty). The Omnibus Test of Model Coefficients produced a significant chi-square value which indicates that this model is significantly better than the baseline model $\left(\chi^{2}=33.150, d f=7, p<0.001\right)$. For this model the Nagelkerke R Square value was used $(r=0.114)$; this model accounts for $11.4 \%$ of the variance. This model correctly predicted $62.4 \%$ of participant ratings. The interaction term between age and any type of memory error was a non-significant predictor of the defendant being rated as not guilty at the .05 level $(p=0.628)$. 
The overall child age condition was a non-significant predictor of the defendant being rated as not guilty at the .05 level $(p=0.640)$. The overall memory error condition was a significant predictor of the defendant being rated as not guilty at the .05 level (Wald=8.252, $d f=$ $3, p<0.05)$. The major reconstructive error condition was a significant predictor of the defendant being rated as not guilty $(\beta=3.747, d f=1, p<0.01)$. These results indicate that when a child made a major reconstructive error the participant was 3.75 times more likely to rate the defendant as not guilty. The minor reconstructive error was a non-significant predictor of the defendant being rated as not guilty ( $p=0.100)$. The source monitoring error condition was a significant predictor of the defendant being rated as not guilty $(\beta=2.372, d f=1, p<0.05)$. The results indicate that when a child made a source monitoring error the participant was 2.37 times more likely to rate the defendant as not guilty.

Another logistic regression was conducted to determine if child age and/or a memory error predicted child credibility (credible vs. not credible). The Omnibus Test of Model Coefficients produced a significant chi-square value which indicates that this model is significantly better than the baseline model $\left(\chi^{2}=36.335, d f=7, p<0.001\right)$. For this model the Nagelkerke R Square value was used ( $r=0.125)$; this model accounts for $12.5 \%$ of the variance. This model correctly predicted $63.7 \%$ of participant ratings. The interaction term between age and any type of memory error was a non-significant predictor of the child being rated as not credible at the .05 level $(p=0.629)$.

The overall age condition was a non-significant predictor of the child being rated as not credible ( $p=0.687$ ). The overall memory condition was a significant predictor of the child being rated as not credible (Wald=9.782, $d f=3, p<0.05$ ). The Major Reconstructive error condition was a significant predictor of the child being rated as not credible $(\beta=4.667, d f=1, p<0.01)$. These 
results indicate that when a child made a major reconstructive error the participant was 4.67 times more likely to rate the child as not credible. The minor reconstructive error was a significant predictor of the defendant being rated as not credible $(\beta=2.50, d f=1, p<0.05)$. These results indicate that when the child made a source monitoring error the participant was 2.5 times more likely to rate the child as not credible. The source monitoring error condition was a significant predictor of the child being rated as not credible $(\beta=2.471, d f=1, p<0.043)$. The results indicate that when a child made a source monitoring error the participant was 2.47 times more likely to rate the child as not credible.

\section{Discussion}

The results of this study help to broaden our understanding of how memory errors affect the credibility of a witness and the perceived guilt of a defendant. It was hypothesized based on Krackow (2018) that 6-year-old child witnesses would be rated as less credible, more subject to external influences, and the defendant would be rated as less guilty across all memory conditions when compared to a control condition. These findings support this original hypothesis. There was no hypothesis made about if age differences (4-year-olds vs. 6-year-olds) would be present between any of the memory error conditions. Therefore, no matter the age of a child (4 vs. 6) if a memory error, of any kind, was made the child was viewed as less credible, they were viewed as more subject to external influences, and the defendant was viewed as less guilty.

It is important to note that there were no differences between the memory error conditions. This indicates that potential jurors are not discriminating between types of memory error. Based on the data, it appears that if a child makes any kind of memory error while testifying, a juror may perceive that error as damaging to the child's testimony and potentially beneficial to the defendant's outcome. Additionally potential jurors are not discriminating 
between the ages of the child witnesses. The data show that when potential jurors are presented with testimony from a 4-and 6-year-old child witness there is no difference in how they perceive the child witness regardless of whether the child makes a memory error.

Another important finding from this study was the gender differences on child credibility, external influences, and defendant guilt. The Cohen's $d$ values indicated that there were moderate effect sizes on all three measures. It was determined that females were rating the child as more credible, less subject to external influences, and the defendant as more guilty when compared to the male participants. The important implications from these results are that females will likely be more forgiving in their overall perceptions of the child regardless of whether they make a memory error while testifying.

An interesting result that should be highlighted is that making a memory error is a significant predictor for the defendant being rated as not guilty. The only individual memory error condition that was a significant predictor was the major reconstructive error condition. When a child makes a major reconstructive memory error a potential juror is nearly 4 times less likely to rate the defendant as guilty. This is extremely important information for a prosecutor to understand because one error made by the child might undo the work the prosecutor has done to build up their case. The differences in child age were not significant predictors of potential jurors rating the defendant as not guilty.

Making a memory error of any kind was a significant predictor of the child being rated as not credible. Based on the results, if a child makes a memory error of any kind a potential juror is anywhere from 2.47 times to 5 times more likely to rate the child as not credible. Much like the not guilty rating for the defendant, this not credible rating of the child has the same implications for the prosecution. 
All of these results point to the same conclusion, at some level when a child makes a memory error, that memory error can damage the child's perceived credibility, the belief that they are subject to external influences, and the defendant will be viewed as less guilty. This study helps to introduce evidence to a previously under-researched area. The most important takeaway from these findings is that regardless of the age of child and regardless of the type of memory error a child makes, they may be viewed as less credible, more subject to external influences, and the defendant may be seen as less guilty. These findings have important implications for the legal system. Many times children will testify about alleged abuse, because that is a common way to gain convictions when there is no physical evidence. Those who chose to prosecute abuse cases and those who decide that children need to testify should greatly consider the implications a memory error could have on the child's credibility as well as the guilt of the defendant. It has already been shown in the literature that memory is a naturally fallible process, and it is not uncommon for people to make memory errors on a daily basis (Brainerd \& Reyna, 1998; Hudson, 1990). It should be decided that the benefits outweigh the costs before a child is put in a position where a large portion of the case is resting on a naturally flawed process. Prosecutors should also use this information to educate jurors about how common memory errors are, as well as the potential effects a memory error might have on their perception of the child and the defendant.

It should be noted that specifically for defendant guilt a trend emerged when further exploring possible age differences. Though the main effect of age was not significant, a trend emerged that participants rated the defendant as more guilty when the child witness was 4-yearsold when compared to a 6-year-old child witness. While this main effect is not significant this 
trend could indicate there is the potential that the age of the child witness is in some way affecting the perceived defendant guilt.

\section{Limitations}

A limitation of this study was that it was conducted using Amazon Mechanical Turk. While we attempted to put few restrictions on who could participate in the study, using this online resource does not produce a truly representative sample of all potential jurors. It has been shown that MTurk samples share similar qualities to more traditional samples made up of students and community members, but there are some distinct differences that may affect sample quality. It has been shown that MTurk samples tend to pay less attention to the experimental materials and that they will often seek answers online while completing the survey, even when correct answers are not a requirement for payment (Goodman, Cryder, and Cheema, 2013). MTurk samples do tend to be more diverse than a general population samples; it is not truly representative of the United States' or even world's population (Paolacci \& Chandler, 2014). It has been shown that MTurk samples are generally younger, more educated, and less employed than a general population sample (Paolacci \& Chandler, 2014). These are important pieces of information that could affect the data collected from MTurk but could also provide strengths not gained in using a tradition sample.

\section{Future Directions}

While this study did have certain limitations, it did produce a good amount of knowledge, as well as, opened up some new potential questions. Using testimony about sexual abuse is an emotionally salient topic for many people. This study could be replicated using different vignettes that address other reasons a child might be testifying. The vignettes could cover 
physical abuse, neglect, or even witnessing a crime. It would be interesting to see whether jurors' perceptions of memory errors change based on the context of the crime the child is referencing. This study should also be replicated with an in-person sample. It would be important to understand how seeing a child give testimony and make a memory error differs from a person reading about it. Having participants sit in a courtroom and hear a child giving testimony in person compared to them reading about a fictional child, could alter how they chose to interpret the memory error. It would be a necessary step for prosecutors to understand the effects of memory errors, as well as the effects of having the child present in the room. 


\section{Appendix A: Results Tables}

Table 1

Age Condition: Estimated Marginal Means (Child Credibility)

\begin{tabular}{lccc}
\hline Age Condition & $M$ & $S D$ & $95 \%$ CI \\
& & & \\
\hline 4 years old & 5.88 & 0.18 & $5.52-6.24$ \\
6 years old & 5.66 & 0.18 & $5.30-6.02$
\end{tabular}

Notes. Means are based on a 1-10 scale.

Table 2

Memory Error Condition: Estimated Marginal Means (Child Credibility)

\begin{tabular}{lcccc}
\hline Memory Error Condition & $M$ & $S D$ & $95 \%$ CI & $p$ \\
& & & & \\
\hline Major & 5.13 & 0.28 & $4.57-5.69$ & 0.001 \\
Minor & 5.42 & 0.25 & $4.92-5.92$ & 0.001 \\
SM & 5.42 & 0.26 & $4.92-5.92$ & 0.001 \\
Control & 7.11 & 0.24 & $6.64-7.58$ & 0.001
\end{tabular}

Notes. Means are based on a 1-10 scale. Major = Major Reconstructive Error. Minor = Minor Reconstructive Error. SM. = Source Monitoring Error. 
Table 3

Age and Memory Error interaction term: Estimated Marginal Means (Child Credibility)

\begin{tabular}{lccc} 
Condition & $M$ & SD & $95 \%$ CI \\
\hline 4 yrs*Major & 5.34 & 0.41 & $4.53-6.16$ \\
4 yrs*Minor & 5.68 & 0.35 & $4.99-6.37$ \\
4 yrs*SM & 5.47 & 0.32 & $4.84-6.10$ \\
4 yrs*Control & 7.03 & 0.36 & $6.31-7.75$ \\
6 yrs*Major & 4.92 & 0.39 & $4.16-5.68$ \\
6 yrs*Minor & 5.16 & 0.36 & $4.45-5.88$ \\
6 yrs*SM & 5.37 & 0.40 & $4.59-6.15$ \\
6 yrs*Control & 7.19 & 0.31 & $6.58-7.79$
\end{tabular}

Notes. Means are based on a 1-10 scale. Major = Major Reconstructive Error. Minor = Minor Reconstructive Error. SM. = Source Monitoring Error.

Table 4

Age Condition: Estimated Marginal Means (Defendant Guilt)

Age Condition $\quad M \quad$ SD $\quad 95 \%$ CI

\begin{tabular}{lccc}
\hline 4 years old & 6.05 & 0.19 & $5.68-6.41$ \\
6 years old & 5.59 & 0.19 & $5.22-5.96$
\end{tabular}

Notes. Means are based on a 1-10 scale. 
Table 5

Memory Error Condition: Estimated Marginal Means (Defendant Guilt)

\begin{tabular}{lcccc}
\hline Memory Error Condition & $M$ & SD & $95 \%$ CI & $p$ \\
& & & & \\
\hline Major & 5.06 & 0.29 & $4.49-5.63$ & 0.001 \\
Minor & 5.53 & 0.26 & $5.02-6.04$ & 0.001 \\
SM & 5.55 & 0.26 & $5.03-5.07$ & 0.001 \\
Control & 7.14 & 0.25 & $6.66-7.62$ & 0.001
\end{tabular}

Notes. Means are based on a 1-10 scale. Major $=$ Major Reconstructive Error. Minor $=$ Minor Reconstructive Error. SM. = Source Monitoring Error.

Table 6

Age and Memory Error interaction term: Estimated Marginal Means (Defendant Guilt)

\begin{tabular}{lccc} 
Condition & $M$ & SD & $95 \%$ CI \\
\hline 4 yrs*Major & 5.31 & 0.43 & $4.48-6.15$ \\
4 yrs*Minor & 6.04 & 0.36 & $5.33-6.76$ \\
4 yrs*SM & 5.58 & 0.33 & $4.93-6.23$ \\
4 yrs*Control & 7.24 & 0.38 & $6.51-7.98$ \\
6 yrs*Major & 4.80 & 0.40 & $4.02-5.58$ \\
6 yrs*Minor & 5.02 & 0.38 & $4.28-5.75$ \\
6 yrs*SM & 5.52 & 0.41 & $4.72-6.32$ \\
6 yrs*Control & 7.04 & 0.32 & $6.41-7.66$
\end{tabular}

Notes. Means are based on a 1-10 scale. Major = Major Reconstructive Error. Minor = Minor Reconstructive Error. SM. = Source Monitoring Error. 
Table 7

Age Condition: Estimated Marginal Means (External Influences)

Age Condition $\quad M \quad$ SD $\quad 95 \%$ CI

\begin{tabular}{lccc}
\hline 4 years old & 5.06 & 0.18 & $4.71-5.40$ \\
6 years old & 5.19 & 0.18 & $4.84-5.53$
\end{tabular}

Notes. Means are based on a 1-10 scale.

Table 8

Memory Error Condition: Estimated Marginal Means (External Influences)

\begin{tabular}{lcccc}
\hline & & & & \\
Memory Error Condition & $M$ & SD & $95 \%$ CI & $p$ \\
& & & & \\
\hline Major & 5.39 & 0.27 & $4.86-5.93$ & 0.001 \\
Minor & 5.73 & 0.24 & $5.26-6.21$ & 0.001 \\
SM & 5.57 & 0.25 & $5.09-6.05$ & 0.001 \\
Control & 3.79 & 0.23 & $3.34-4.24$ & 0.001
\end{tabular}

Notes. Means are based on a 1-10 scale. Major = Major Reconstructive Error. Minor = Minor Reconstructive Error. SM. = Source Monitoring Error. 
Table 9

Age and Memory Error interaction term: Estimated Marginal Means (External Influences)

\begin{tabular}{lccc} 
Condition & $M$ & SD & $95 \%$ CI \\
\hline 4 yrs*Major & 5.20 & 0.40 & $4.42-5.98$ \\
4 yrs*Minor & 5.48 & 0.34 & $4.81-6.14$ \\
4 yrs*SM & 5.71 & 0.31 & $5.10-6.31$ \\
4 yrs*Control & 3.84 & 0.35 & $3.16-4.53$ \\
6 yrs*Major & 5.59 & 0.37 & $4.86-6.32$ \\
6 yrs*Minor & 5.99 & 0.35 & $5.30-6.68$ \\
6 yrs*SM & 5.43 & 0.38 & $4.69-6.18$ \\
6 yrs*Control & 3.73 & 0.30 & $3.15-4.31$
\end{tabular}

Notes. Means are based on a 1-10 scale. Major $=$ Major Reconstructive Error. Minor $=$ Minor Reconstructive Error. SM. = Source Monitoring Error. 


\section{References}

Brainerd, C. J., \& Reyna, V. F. (1998). Fuzzy-Trace Theory and Children’s False Memories. Journal of Experimental Child Psychology, 71(2), 81-129. https://doi.org/10.1006/jecp.1998.2464

Brown, R., \& Kulik, J. (1977). Flashbulb memories. Cognition, 5(1), 73-99. doi:10.1016/00100277(77)90018-X

Bruck, M., London, K., Landa, R., \& Goodman, J. (2007). Autobiographical memory and suggestibility in children with autism spectrum disorder. Development and Psychopathology, 19(1), 73-95. doi:10.1017/S095457940707005

Castelli, P., Goodman, G. S., \& Ghetti, S. (2005). Effects of Interview Style and Witness Age on Perceptions of Children’s Credibility in Sexual Abuse Cases. Journal of Applied Social Psychology, 35(2), 297-317. doi:10.1111/j.1559-1816.2005.tb02122.x

Ceci, S. J., \& Bruck, M. (2005). Jeopardy in the courtroom: A scientific analysis of children's testimony. Washington, DC: American Psychological Association.

Giles, J. W., Gopnik, A., \& Heyman, G. D. (2002). Source Monitoring Reduces the Suggestibility of Preschool Children. Psychological Science, 13(3), 288-291. https://doi.org/10.1111/1467-9280.00453

Goodman, G. S., \& Reed, R. S. (1986). Age differences in eyewitness testimony. Law and Human Behavior, 10(4), 317-332. http://dx.doi.org/10.1007/BF01047344

Goodman, G. S., Golding, J. M., Helgeson, V. S., Haith, M. M., \& Michelli, J. (1987). When a child takes the stand: Jurors perceptions of childrens eyewitness testimony. Law and Human Behavior, 11(1), 27-40. doi:10.1007/bf01044837 
Goodman, G. S., Hirschman, J. E., Hepps, D., \& Rudy, L. (1991). Children's memory for stressful events. Merrill-Palmer Quarterly, 37(1), 109-157.

Goodman, J. K., Cryder, C. E., \& Cheema, A. (2012). Data Collection in a Flat World: The Strengths and Weaknesses of Mechanical Turk Samples. Journal of Behavioral Decision Making, 26(3), 213-224. doi:10.1002/bdm.1753

Hudson, J. A. (1990). Constructive processing in children’s event memory. Developmental Psychology, 26(2), 180-187. https://doi.org/10.1037/0012-1649.26.2.180

Johnson, M. K., Hashtroudi, S., \& Lindsay, D. S. (1993). Source monitoring. Psychological Bulletin, 114(1), 3-28. https://doi.org/10.1037/0033-2909.114.1.3

Krackow, E. (2015). Clinical Interviewing in Child Sexual Abuse Cases. In R. Cautin \& S. Lilienfeld (Eds.). Encyclopedia of Clinical Psychology. New York Wiley

Krackow, E. (2018). Adults’ perceptions of child maltreatment allegations: Parental coaching, accuracy of children's factual autobiographical recall and expert witness acumen. Manuscript submitted for publication.

Krackow, E. (in press). Clinical and forensic interviewing of children and adults with autism spectrum disorder: Strategies for improving eyewitness reports. To appear in Johnson, J., Goodman, G. S., \& Mundy, P.(Eds). Memory, autism spectrum disorder, and the law. New York, Wiley.

Krackow, E., \& Longo, A. (2016). The effects of memory recovery techniques on jurors’ perceptions of recovered memories. International Journal of Psychological Studies, 8(3), 188-193. doi: 10.5539/ijps.v8n3188

Krackow, E., Kania, K., \& Travers, R. M. (2012). Does Negative Mood Confer an Advantage in 
the Recall of Negative Life Events? Imagination, Cognition and Personality, 32(3), 291305. https://doi.org/10.2190/IC.32.3.e

Krackow, E., \& Lynn, S. J. (2009). Event report training: An examination of the efficacy of a new intervention to improve childrens eyewitness reports. Applied Cognitive Psychology, 24(6), 868-884. doi:10.1002/acp.1594

Krackow, E., Lynn, S. J., \& Payne, D. G. (2005-2006). The death of Princess Diana: The effects of memory enhancement procedures on flashbulb memories. Imagination, Cognition \& Personality, 25, 197-219

Lindsay, D. S., \& Johnson, M. K. (1989). The eyewitness suggestibility effect and memory for source. Memory \& Cognition, 17(3), 349-358. https://doi.org/10.3758/BF03198473

Mitchell, K. J., Johnson, M. K., \& Mather, M. (2003). Source monitoring and suggestibility to misinformation: adult age-related differences. Applied Cognitive Psychology, 17(1), 107119. https://doi.org/10.1002/acp.857

Orcutt, H. K., Goodman, G. S., Tobey, A. E., Batterman-Faunce, J. M., \& Thomas, S. (2001). Detecting deception in children's testimony. Factfinders abilities to reach the truth in open court and closed-circuit trials. Law and Human Behavior, 25(4), 339-372. http://dx.doi.org/10.1032/A:1010603618330

Otgaar, H. P., Candel, I. E. L., Scoboria, A., \& Merckelbach, H. L. G. J. (2010). Script knowledge enhances the development of children's false memories. Acta Psychologica, 133(1), 57-63. DOI: 10.1016/j.actpsy.2009.09.002

Paolacci, G., \& Chandler, J. (2014). Inside the Turk:Understanding Mechanical Turk as a Participant Pool. Current Directions in Psychological Science, 23(3), 184-188. doi:10.1177/0963721414531598 
Tessier. P. \& Krackow, E. (2013). The effects of interviewing technique and research evidence on jurors' perceptions of child witnesses. Poster presented at the American PsychologyLaw Society Meetings.

Thierry, K. L., \& Spence, M. J. (2002). Source-monitoring training facilitates preschoolers’ eyewitness memory performance. Developmental Psychology, 38(3), 428-437. https://doi.org/10.1037/0012-1649.38.3.428

Welch-Ross, M. K., Diecidue, K., \& Miller, S. A. (1997). Young children’s understanding of conflicting mental representation predicts suggestibility. Developmental Psychology, 33(1), 43-53. https://doi.org/10.1037/0012-1649.33.1.43

Wise, R., Fishman, C., \& Safer, M. (2009). How to Analyze the Accuracy of Eyewitness Testimony in a Criminal Case. Connecticut Law Review, 42.

Zaragoza, M. S., \& Lane, S. M. (1994). Source misattributions and the suggestibility of eyewitness memory. Journal of Experimental Psychology: Learning, Memory, and Cognition, 20(4), 934-945. https://doi.org/10.1037/0278-7393.20.4.934 